\title{
A hillslope scale model for quantifying fluxes of weathered elements in a mountainous headwater catchment
}

Bhavna Arora ${ }^{1}$, Sergio CARrero ${ }^{2}$, CARl SteEFel $^{3}$, BEN GILBERT $^{4}$

${ }^{1}$ Lawrence Berkeley Laboratory, CA, barora@1bl.gov

${ }^{2} \mathrm{UC}$ Berkeley, CA, sergio.carrero@berkeley.edu

${ }^{3}$ Lawrence Berkeley Laboratory, CA, bgilbert@lbl.gov

${ }^{4}$ Lawrence Berkeley Laboratory, CA, cisteefel@1bl.gov

Although weathering fluxes from hilltops to valleys are important for downstream water quality, current geochemical modeling of weathering has been largely limited to 1-D representations. Without the explicit consideration of topographic gradients as well as lateral fluid and solid transport that are important in mountainous settings, the prediction of future weathering contributions to river quality remain uncertain. The objective of this work is to conduct a hillslope-scale treatment of weathering fluxes, while accounting for the impacts of short-term climatic perturbations on hillslope exports. Here, we focus on a mountainous headwater catchment of the East River, Colorado where significant year-to-year variations in snowpack accumulation and snowmelt timing have been observed. For this purpose, a hillslope-to-floodplain transect model has been developed using TOUGHREACT. The model, making use of the EOS9 module, specifically accounts for mineral and functional microbial populations in the subsurface, and can resolve vertical and lateral hydrologic and biogeochemical fluxes along the hillslope transect. In particular, we compare the process couplings and mechanisms that guide nutrient and elemental fluxes from hilslopes underlain by a mineralized bedrock with high sulfide mineral content.

Concentration discharge relationships at a monitoring station downgradient of the hillslope transect suggest that the stream is enriched in magnesium, chloride and dissolved inorganic carbon, and majorly depleted in nitrate and sulfate during snowmelt. Model results further demonstrate that hillslope contributions to the stream vary between 55 and $58 \%$ for elemental fluxes across years. Model results demonstrate spatially distinct pyrite and dolomite reaction fronts in the upslope regions as compared to the collocated reaction fronts within the floodplain. Overall, these findings demonstrate the significant lateral connection that impacts elemental fluxes and weathering reaction fronts along the hillslope. 